\title{
Aplicação do Design Thinking como ferramenta de inovação na gestão de projetos no setor metalúrgico
}

\author{
Application of design thinking as an innovation tool in project management in metallurgical sector \\ Aplicación del design thinking como herramienta de innovación en la gestión de proyectos en el \\ sector metalúrgico
}

Recebido: 24/06/2021 | Revisado: 30/06/2021 | Aceito: 03/07/2021 | Publicado: 15/07/2021

\author{
Bruno Ribeiro de Carvalho \\ ORCID: https://orcid.org/0000-0002-7590-9783 \\ Centro Universitário Teresa D’Ávila, Brasil \\ E-mail: bruno.carvalho@2bsmartconsulting.com \\ Rosinei Batista Ribeiro \\ ORCID: https://orcid.org/0000-0001-8225-7819 \\ Centro Universitário Teresa D’Ávila, Brasil \\ E-mail: rosinei1971@gmail.com \\ Celi Langhi \\ ORCID: https://orcid.org/0000-0002-5527-2412 \\ Centro Estadual de Educação Tecnológica Paula Souza, Brasil \\ E-mail: celi@infolearning.com.br \\ Simone Pereira Taguchi Borges \\ ORCID: https://orcid.org/0000-0002-7192-0950 \\ Universidade Federal Rural do Rio de Janeiro, Brasil \\ E-mail: simoneptb@hotmail.com.br \\ Adriano José Sorbile de Souza \\ ORCID: https://orcid.org/0000-0002-6612-1396 \\ Centro Universitário Teresa D’Ávila, Brasil \\ E-mail: adriano.sorbile@gmail.com \\ José Wilson de Jesus Silva \\ ORCID: https://orcid.org/0000-0002-0033-2270 \\ Centro Universitário Teresa D’Ávila, Brasil \\ E-mail: jwjsilva@gmail.com
}

\begin{abstract}
Resumo
Este trabalho consiste em demonstrar como o Design Thinking, contribui na integração entre as pessoas e os resultados das organizações que utilizam essa metodologia. A pesquisa tem como objetivo avaliar o potential ganho da utlização de metodologias inovadoras, como o Design Thinking em gestão de projetos. A metodologia de pesquisa é do tipo exploratório-descritiva, de natureza qualitativa, com a experiência do autor que atua na área de pesquisa. Para atingir os objetivos pretendidos, o estudo se apoia em questionários aplicados aos profissionais que utilizam dessas ferramentas. Também foi considerado um workshop sobre Design Thinking e sua aplicação em projetos, por meio de consulta ao material bibliográfico do professor especialista do curso de MBA em gestão de projetos, que foi concluído com êxito pelo autor. Para a obtenção dos dados, foi realizada uma análise descritiva do treinamento "in company" numa empresa do setor automotivo, uma multinacional do setor metalúrgico, sediada em Taubaté-SP. Para isso, aplicou-se um treinamento de gestão de comunicação e projetos com a participação de 20 colaboradores, utilizando, nesse encontro, metodologias ativas de gestão de projetos. As etapas foram: brainstorming; análise dos problemas; conscientização e nivelamento de conceito; estudos de casos reais de sucesso e insucesso; e prática com ferramenta de inovação e metodologia ágil e atividades com base nos processos da empresa. Através de uma análise qualitativa e entrevista de diagnóstico com a liderança da empresa, foi identificado que a gestão de projetos de clientes estava carente de métodos inovadores, bem como de indicadores de gestão que pudesse melhorar os resultados esperados nos projetos contratados. Então, o foco foi trabalhar na melhoria dos processos de gestão de projetos, introduzindo ferramentas de inovação como Design Thinking, Canvas e metodologias fundamentadas nas melhores práticas de gestão de projetos do PMI (Project Management Institute). Conclui-se que metodologias ativas, apoiadas em um sistema robusto de gestão, possibilitam gerar inovações quando empregadas e disseminadas como prática de gestão e com envolvimento de pessoas dos diversos níveis organizacionais e, principalmente, gerar melhores resultados nos projetos conduzidos pela organização.
\end{abstract}

Palavras-chave: Design thinking; Gestão de projetos; Comunicação; Inovação. 


\begin{abstract}
This work consists of demonstrating how Design Thinking as an innovation tool in project management contributes to the integration between people and the results of organizations that use this methodology. The research aims to assess the potential gain of using innovative methodologies such as Design Thinking in project management. The research methodology is exploratory-descriptive, qualitative in nature, using bibliographic research methods and taking credit for the experience of the author who works in the research area. To achieve the intended objectives, the study is based on questionnaires applied to professionals who use these tools. A workshop on Design Thinking and its application in projects was also considered, through consultation of the material of specialist professors from the MBA course in project management, which the author participated and successfully concluded. To obtain the data, a descriptive analysis of in-company training was performed in a company in the automotive sector, a multinational in the metallurgical sector, headquartered in Taubaté-SP. For this, a communication and project management training was applied, with the participation of 20 employees, using, in this meeting, active project management methodologies. The steps were: Brainstorming; Problem analysis; concept awareness and leveling; real case studies of success and failure; and practice with an agile innovation and methodology tool and activities based on the company's processes. Through a qualitative analysis, diagnostic interview with the company's leadership, it was identified that the management of client projects was lacking in innovative methods, as well as management indicators that could improve the expected results in the contracted projects. So the focus was to work on improving project management processes, introducing innovation tools such as Design Thinking, Canvas and methodologies based on the best project management practices of the PMI (Project Management Institute). It is concluded that active methodologies supported by a robust management system make it possible to generate innovations when used and disseminated as a management practice and with the involvement of people from different organizational levels and, mainly, to generate better results in the projects conducted by the organization.
\end{abstract}

Keywords: Design thinking; Project management; Communication; Innovation.

\title{
Resumen
}

Este trabajo consiste en demostrar cómo el Design Thinking como herramienta de innovación en la gestión de proyectos contribuye a la integración entre las personas y los resultados de las organizaciones que utilizan esta metodología. La investigación tiene como objetivo evaluar la ganancia potencial del uso de metodologías innovadoras como Design Thinking en la gestión de proyectos. La metodología de investigación es exploratoria-descriptiva, de carácter cualitativo, utilizando métodos de investigación bibliográfica y atribuyéndose el mérito a la experiencia del autor que trabaja en el área de investigación. Para lograr los objetivos previstos, el estudio se basa en cuestionarios aplicados a los profesionales que utilizan estas herramientas. También se consideró un taller sobre Design Thinking y su aplicación en proyectos, a través de la consulta del material de profesores especialistas del curso MBA en gestión de proyectos, en el que el autor participó y concluyó con éxito. Para la obtención de los datos se realizó un análisis descriptivo de la formación in-company en una empresa del sector de la automoción, multinacional del sector metalúrgico, con sede en Taubaté-SP. Para ello, se aplicó una capacitación en comunicación y gestión de proyectos, con la participación de 20 empleados, utilizando en este encuentro metodologías activas de gestión de proyectos. Los pasos fueron: Lluvia de ideas; Análisis del problema; concienciación y nivelación de conceptos; estudios de casos reales de éxito y fracaso; y practicar con una herramienta ágil de innovación y metodología y actividades basadas en los procesos de la empresa. Mediante un análisis cualitativo, entrevista de diagnóstico con el liderazgo de la empresa, se identificó que la gestión de los proyectos de los clientes carecía de métodos innovadores, así como de indicadores de gestión que pudieran mejorar los resultados esperados en los proyectos contratados. Por lo que el enfoque fue trabajar en la mejora de los procesos de gestión de proyectos, introduciendo herramientas de innovación como Design Thinking, Canvas y metodologías basadas en las mejores prácticas de gestión de proyectos del PMI (Project Management Institute). Se concluye que las metodologías activas sustentadas en un sistema de gestión robusto permiten generar innovaciones cuando se utilizan y difunden como una práctica de gestión y con la participación de personas de diferentes niveles organizacionales $y$, principalmente, para generar mejores resultados en los proyectos que lleva a cabo la organización.

Palabras clave: Design thinking; Gestión de proyectos; Comunicación; Innovación.

\section{Introdução}

A gestão de projetos é um componente importante do dia a dia de qualquer negócio. Todas as empresas que entregam produtos e serviços de qualidade devem ter uma boa metodologia e executar uma gestão de projetos eficaz e inteligente, Ulrich (2014) e Paschini (2006) afirmam que bons projetos são necessários às ações que fogem da rotina e que possam contribuir e impactar o negócio.

Podendo ser aplicado nos desafios e problemas das mais diversas complexidades, o Design Thinking propõe a "[...] adoção de um ponto de vista empático com os clientes e usuários no centro do desenvolvimento de qualquer projeto" (Brown, 
2010; Bayer, 2017).

Nesse contexto, podemos entender que o Design Thinking tende a ser uma abordagem importante para o pensamento projetual (que tem objetivo, início, meio e fim definidos), de modo a contribuir para que toda organização construa e gerencie seus projetos estratégicos com uma boa gestão de comunicação interpessoal gerando assim mais efetividade e empatia junto às partes interessadas.

Entretanto, quanto os profissionais de gestão de projetos conhecem sobre o tema? Será que eles usam o Design Thinking? A fim de eliminar os riscos de que esse estudo possa trazer resultados incorretos, entende-se que uma possível explanação seria a de garantir um nivelamento de conhecimento sobre a abordagem do Design Thinking e a compreensão prática de como pode ser utilizado na gestão de projetos.

Por conta disso, esta pesquisa está baseada em um treinamento aplicado a profissionais que atuam com gestão de projetos tradicional sendo proposta a utilização de metodologias inovadoras de gestão e integração, e como referência, destacase o Canvas e o Design Thinking.

Portanto, o objetivo deste trabalho foi demonstrar que o modelo inovador do Design Thinking aplicado na gestão de projetos e processos contribuiu muito na integração das pessoas e na competitividade das empresas.

\subsection{Diagnóstico da situação-problema e oportunidade}

Sabe-se que a gestão de projetos é muito importante para os resultados empresariais. "É recorrente ouvirmos especialistas em negócios, presidentes e diretores de empresas dizerem que o grande diferencial estratégico está nas pessoas" (Calôba, 2018; Poikela, 2006).

Mas qual é a expectativa das empresas em relação ao papel da Gestão de Projetos? As empresas estão cada vez mais projetizadas e suas ações de gestão de projetos têm sido cada vez mais demandadas para uma atuação mais estratégica e com forte impacto na capacitação e engajamento das equipes e também nos resultados do negócio.

Thompson (2007) e Yalgosheva (2020) afirmam que a gestão deve buscar eficiência em vez de valor. Esse argumento também é uma realidade na gestão de projetos, o que se via antes era apenas o foco no cumprimento das metas, hoje o foco é qual valor o projeto entrega para o cliente. Provavelmente porque é mais fácil de mensurar. Não se refere apenas à qualidade dos processos proporcionados aos funcionários e aos gerentes, mas também aos benefícios gerados para acionistas e clientes. Cabe ao board (Conselhho diretivo da empresa) ajudar os departamentos a atingirem as metas da empresa. Em gerenciamento de projetos, o gerente deve ser capaz de fazer essa gestão para que a equipe do projeto trabalhe alinhada e engajada na obtenção dos resultados esperados dos projetos.

Dessa forma, percebe-se que a gestão de projetos tem grande contribuição aos negócios, porém, “[...] ainda falta mais proatividade e eficácia nas ações, sejam pela obtenção dos resultados diretos ou mesmo pelo envolvimento desses gestores na elaboração e condução de projetos que impactam nos colaboradores da empresa" (Thompson, 2007; Yalgosheva, 2020).

Bersin (2016) e Boudreau (2017) previram que as equipes deixarão de projetar programas e, em vez disso, projetarão experiências de alto valor e integração que estimulem, envolvam e inspiram empregados.

O profissional de Gestão de Projetos deve ser um parceiro do negócio. Segundo Novaes (2017) e Raynor (2017), discutir e refletir sobre as questões que envolvem as pessoas e a aplicabilidade dos projetos em que elas se inserem é uma necessidade recorrente para as empresas e profissionais que militam nesses processos.

Propor novas formas de gerir projetos é um estímulo ao modo convencional e uma alternativa para conseguir maior eficácia pela perspectiva das necessidades e interesses dos principais envolvidos. "Práticas inovadoras de projetos podem se tornar um diferencial para estimular a participação das pessoas e a efetividade dos resultados esperados" (Finocchio, 2013; 
Layton, 2020).

Com fundamentação no pensamento projetual, cria-se a oportunidade de aplicar o "[...] Design Thinking como base para inovar e estabelecer novos parâmetros de engajamento, empatia, estruturação e prototipação que não fiquem presos somente à opinião e experiência centradas nos projetistas" (Liedtka, 2016; Logan, 2012), atingindo maior compreensão dos problemas e do contexto e ampliando o envolvimento de todas as partes interessadas (mais importante de qualquer projeto) e impactadas.

A partir da proposta do pensamento projetual em gestão de projetos, é possível obter as melhores práticas com relação às necessidades estratégicas do negócio, gerando maior participação, engajamento e eficácia.

Dessa forma, procurou-se responder à seguinte questão de pesquisa: A metodologia Design Thinking aplicado na Gestão de Projetos tem potencial de impactar positivamente os resultados esperados das empresas?

A hipótese número 1 é de que é possível a utilização da abordagem do Design Thinking na gestão de projetos, e na integração das pessoas. A hipótese número 2 é de que essa abordagem é capaz de gerar melhores resultados de quando não se usa o Design Thinking, e adota-se gestão de projetos tradicional.

Este trabalho tem como metas:

- Avaliar o potencial ganho da utilização de metodologias inovadoras como o Design Thinking em gestão de projetos aplicado em uma empresa do setor metalúrgico;

- Compreender os conceitos do Design Thinking e sua aplicação na gestão de projetos;

- Analisar a importância de gestão de projetos com comunicação assertiva de suas ações com impacto estratégico nos negócios, nos resultados e na relação com os clientes;

- Aplicar experimento controlado em formato de workshop/treinamentos de Design Thinking e comunicação com profissionais de gestão de duas empresas; e

- Diagnosticar sobre as práticas atuais de gestão de projetos e gestão de comunicação em empresas da região Metropolitana do Vale do Paraíba (sub região 2 e 4).

Sendo assim, observa-se a importância do papel do profissional de Gestão de Projetos como um gestor de projetos em si, mas também como orientador das equipes de projetos, como premissa na gestão de recursos humanos na metodologia de gerenciamento de projetos. Também é observado que o estudo teórico se desenvolve com base na revisão da literatura sobre Design Thinking e algumas de suas ferramentas e práticas orientadas para projetos, bem como suas etapas. Para compreender o que isso significa, são apresentados seus principais conceitos e, posteriormente, como eles estão presentes nas organizações e nas empresas (Figura 1). A empatia é primordial para estabelecer conexão entre pessoas, e atender os objetivos que a organização almeja (Alves, 2016; Lourenço, 2021). 
Figura 1 - Mapa da Empatia.

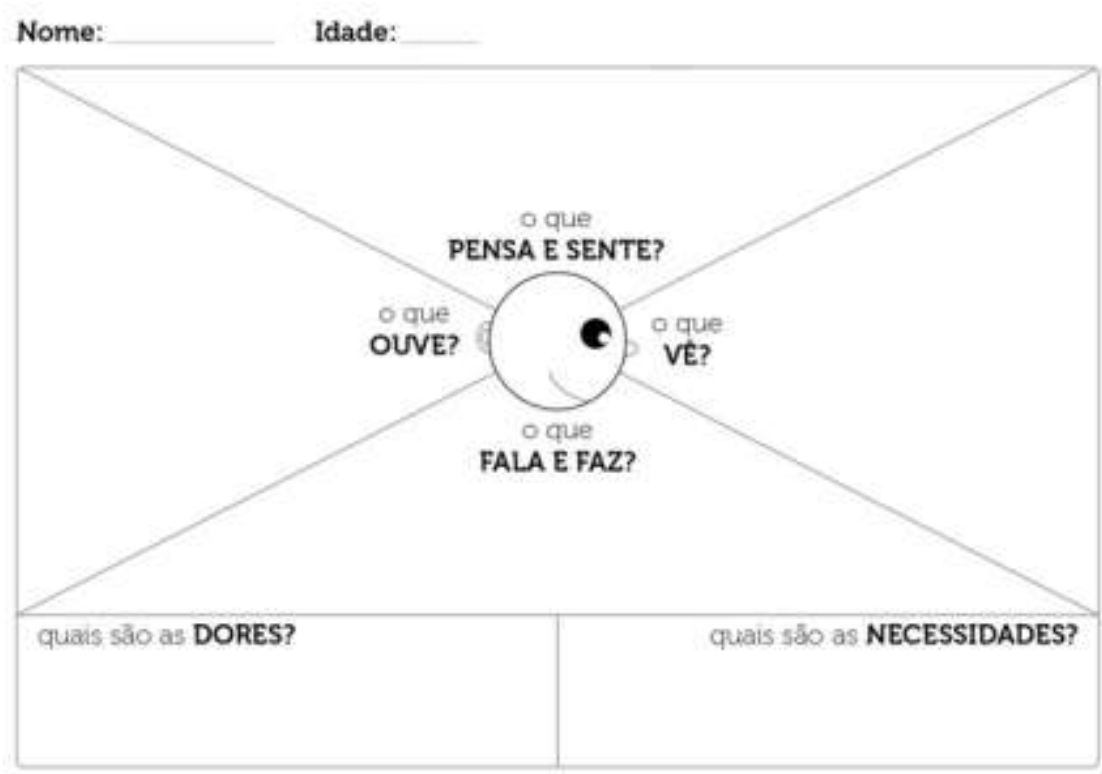

Fonte: Adaptado de Osterwalder (2011).

Durante a fase da imersão, visando à empatia, procura-se:

[...] identificar comportamentos e mapear seus padrões e necessidades. Nesse caso a pesquisa é qualitativa e não pretende esgotar o conhecimento sobre segmentos de consumo e comportamento, mas ao levantar oportunidades de perfis extremos, permite que soluções específicas sejam criadas (Vianna et al., 2012).

A imersão pode ser dividida em duas fases: a fase preliminar e a fase em profundidade. Na fase preliminar, o problema é apresentado ao grupo de design thinkers e o propósito e seus limites começam a ser estabelecidos, onde as áreas de interesse a ser exploradas e são utilizadas para a elaboração dos temas que serão trabalhados na Imersão em Profundidade" (Guldmann, 2019).

$\mathrm{Na}$ fase de imersão em profundidade, são identificados os comportamentos e a partir dele são mapeados os padrões e necessidades latentes (Vianna et al., 2012).

Inicia-se a fase de análise e síntese, onde os dados coletados são organizados de modo visual, com o intuito de apontar os padrões que auxiliem a compreensão do todo, trazendo a identificação de oportunidades e desafios (Vianna et al., 2012). Brown (2010) afirma que "O processo criativo se baseia na síntese, o ato coletivo de juntar as partes para criar ideias completas. Uma vez que os dados foram coletados, é necessário analisá-los e identificar padrões significativos".

Essa etapa inclui a "[...] apresentação, categorização, comparação e análise dos dados coletados na imersão empática" (Melo, 2015; Ben Mahmoud-Jouini, 2016).

O papel dessa etapa é essencial no processo de criar opções e fazer escolhas. Também permite "refinar o problema que deu origem ao desafio estratégico, o qual pode necessitar de revisão após a análise dos dados coletados" (Cavalcanti, 2014; Shivers-McNair et al., 2018).

O intuito da metodologia é avaliar o potencial ganho da utlização de metodologias inovadoras, como o Design Thinking em gestão de projetos, aplicado no setor metalúrgico. Nesse contexto, a proposta da pesquisa foi entender como os profissionais de gestão de projetos de uma empresa do segmento metalúrgico lidam com seus projetos atuais e quais seus respectivos resultados e quais seriam os potenciais resultados com a utilização desse modelo de pensamento de design, 
utilizando o Design Thinking como metodologia, bem como sua base de gestão para os projetos da empresa. Assim sendo, por se tratar da compreensão da problemática de pesquisa enunciada e aos objetivos pretendidos, a pesquisa pode ser classificada como exploratório-descritiva. De acordo com Gonsalves (2011) e Park (2020), pesquisas exploratórias são caracterizadas pelo desenvolvimento e esclarecimento de ideia, ou seja, contribui para o pesquisador ampliar o conhecimento de um determinado fenômeno pouco explorado. Nesse estudo, os efeitos da associação do Design Thinking em gestão de projetos é pouco conhecido. Logo, busca-se explorar a realidade dos profissionais de gestão de projetos e liderança para se obter uma maior compreensão.

Estudos com enfoque descritivo permitem ao pesquisador observar, registrar, analisar e correlacionar fatos ou fenômenos sem, contudo, interferir ou controlar as variáveis interferentes na ocorrência estudada (Cervo, 2007; Tacconi, 2017). Esse tipo de pesquisa visou descobrir a frequência ou a intensidade que determinado fato ocorre e a sua relação com os demais, ou seja, procurou descrever diversas situações e relações, incluindo aspectos do comportamento humano, seja individualmente ou grupos ou comunidades mais complexas.

Vergara (2014) e Lima (2016) ressaltam que a pesquisa descritiva não tem o compromisso de explicar fenômenos, mas serve de base para explicação. Nesse estudo, a investigação interessa-se pelas empresas, a fim de melhor compreender como o Design Thinking pode contribuir para o contexto dos projetos como base para aumentar o potencial de resultados, alinhamento (processos de comunicação) e engajamento dos funcionários.

\section{Metodologia}

\subsection{Plano de desenvolvimento do projeto}

A pesquisa se dá por meio do entendimento junto a diversos profissionais de gestão de projetos de clientes no processo de vendas e desenvolvimento de novos negócios, produtos e/ou serviços, sobre a relevância da aplicação do Design Thinking em projetos. Para isso, a fim de identificar se o Design Thinking pode ser positivo para esse modelo de negócio, um caminho foi o de pesquisar, junto a esse público, o quanto eles usam, como utilizam e quais resultados alcançados quando o Design Thinking e suas ferramentas são utilizadas.

Para nivelar o conhecimento sobre a abordagem do Design Thinking e a compreensão prática de como ele pode ser utilizado em Gestão de Projetos, bem como em seus processos de gestão, entende-se que um bom caminho para isso seria a utilização de um workshop ministrado pelo próprio autor da pesquisa e que envolvesse profissionais de gestão de departamentos variados da empresa, no intuito de averiguar, se o modelo inovador do Design Thinking realmente pode potencializar melhores resultados se comparado com resultados atuais da empresa sem essa nova metodologia.

As pessoas, para não serem identificadas, são denominadas participantes $A, B, C, D, E, F, G, H, I$, e J, sendo considerados os respectivos departamentos de empresa de médio porte (Tabela 1).

Tabela 1 - Participantes da Pesquisa.

\begin{tabular}{|c|c|c|}
\hline Particip. & Depto & $\begin{array}{c}\text { Quantidade de } \\
\text { Participantes }\end{array}$ \\
\hline A & Engenharia & 4 \\
\hline B & Planejamento & 1 \\
\hline C & PCP & 1 \\
\hline D & Produção & 1 \\
\hline E & Compras & 2 \\
\hline F & Comercial & 1 \\
\hline G & Diretoria & 1 \\
\hline H & Manutenção & 1 \\
\hline I & Qualidade & 6 \\
\hline J & Projetos & \\
\hline
\end{tabular}

Fonte: Autores. 
O objetivo foi identificar, junto à empresa, por meio de questionários próprios, como avaliam os resultados dos projetos de diversas naturezas da maneira que são construídos e conduzidos na atualidade, se conheciam a metodologia do Design Thinking, e como seriam os prováveis resultados com a utilização dessa metodologia.

No workshop, utilizou-se metodologia teórica e prática que usa o pensamento projetual do design em projetos e cases com situações reais da empresa. Os participantes puderam experimentar o Design Thinking como uma ferramenta alinhada às metodologias atuais de gestão de projetos para superar os desafios do dia a dia, além de quebrar padrões de pensamento antigos para criar soluções inovadoras com a proposta de aumentar a eficácia dos projetos estratégicos de cada empresas participante.

O Processo metodológico está detalhado e explicado pelas etapas a seguir, e ilustrado conforme a Figura 2.

a) Imersão - Nesse momento, a equipe de projetos aproxima-se do contexto do problema, tanto do ponto de vista da empresa (gestores) quanto do usuário final das ações (funcionários), por meio do levantamento de dados, informações e observações, bem como a criação de insights. Esta etapa deve identificar as dores e necessidades desses públicos, buscando a empatia com eles. Foram apresentadas potenciais ferramentas e ações para a criação de empatia com os usuários do projeto e foi praticado o "mapa da empatia" (Vide Figura 1);

b) Análise e Síntese - Os insights foram organizados de maneira a obterem-se padrões e a criar desafios que auxiliem na compreensão do problema relacionado à gestão de projetos e comunicação (Figura 3). Nessa fase, a equipe precisa identificar as oportunidades e o foco de atuação;

Ideação - Essa fase tem como intuito gerar ideias inovadoras para o tema do projeto ou ação dos envolvidos através do método do brainstorming (Figura 4). Estimular a criatividade e gerar soluções que estejam de acordo com o contexto do assunto trabalhado, estruturando, assim, uma ação específica de gestão de projetos. Foi praticada a definição das oportunidades que devem ser aproveitadas, dificuldades que deviam ser sanadas e os alvos que deviam ser focados. Para proporcionar um exercício prático pelos participantes do workshop, foi elaborada uma ferramenta para ajudar na refinação da proposta, nomeada por alguns autores como "Refinando a Proposta", que é recomendada como melhores práticas de gerenciamento de projetos e processos. O refino das propostas e ideias dos grupos foi realizado pela identificação dos insights percebidos no contexto pesquisado (Figura 5);

Prototipação - Tem a função de auxiliar a validação das ideias geradas, colocando em prática, de maneira rápida e barata, a melhor solução (Figura 6). Cabe ao Gerente de Projeto ou à equipe de trabalho desenvolver o modelo, esboço ou projeto piloto e buscar a validação junto aos usuários e demandantes;

Implementação - Quando a ideia foi desenvolvida em um projeto sólido, foram planejados os próximos passos através do cronograma de implantação, e a identificação de indicadores de acompanhamento e mensuração de resultados. Foram apresentadas sugestões para a execução, através de plano de ação para os projetos desenvolvidos durante o workshop e/ou treinamentos. Ressaltando que cada plano de ação é customizado de acordo com a necessidade de cada empresa, foi possível que os participantes construíssem, durante o workshop, protótipos simples/customizados de soluções inovadoras para cada ou específica demanda da gestão de projetos de suas respectivas empresas. Essa solução ou esse modelo pode ser utilizado em projetos de acordo com a natureza e realidades de cada empresa, se assim desejarem. Importante salientar esse ponto, pois o sucesso se dá pelo nível de interesse e maturidade, não só em gestão de projetos, mas também dos profissionais responsáveis pelas atividades dentro desse escopo de trabalho. 
Figura 2 - Ilustração sobre o modelo de Design Thinking.

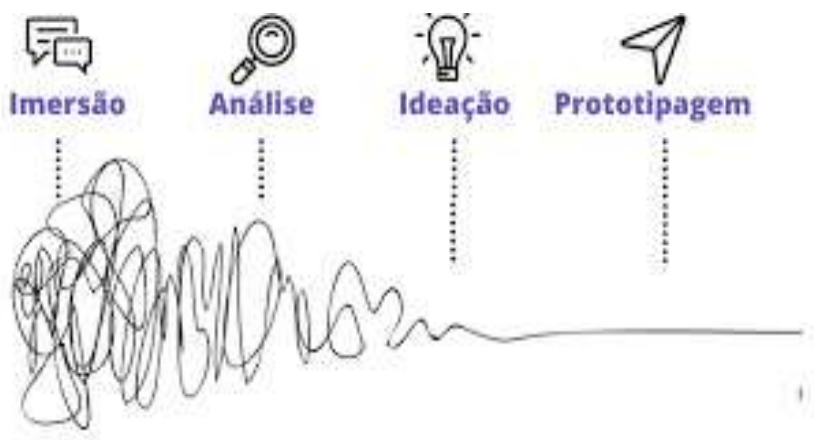

Fonte: Adaptado pelo autor com base no modelo de Vianna et al. (2012)

Figura 3 - Participante preenchendo atividade proposta.

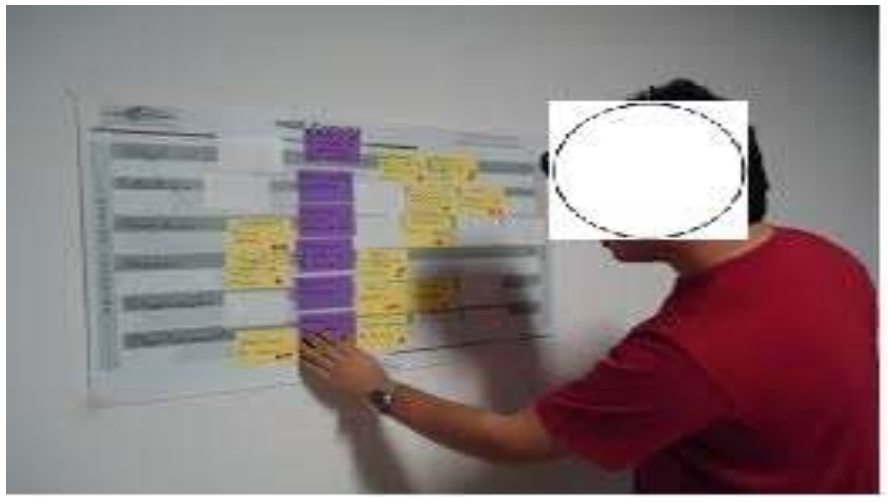

Fonte: Registro fotográfico do autor.

Figura 4 - Momento de brainstorming (tempestade de ideias).

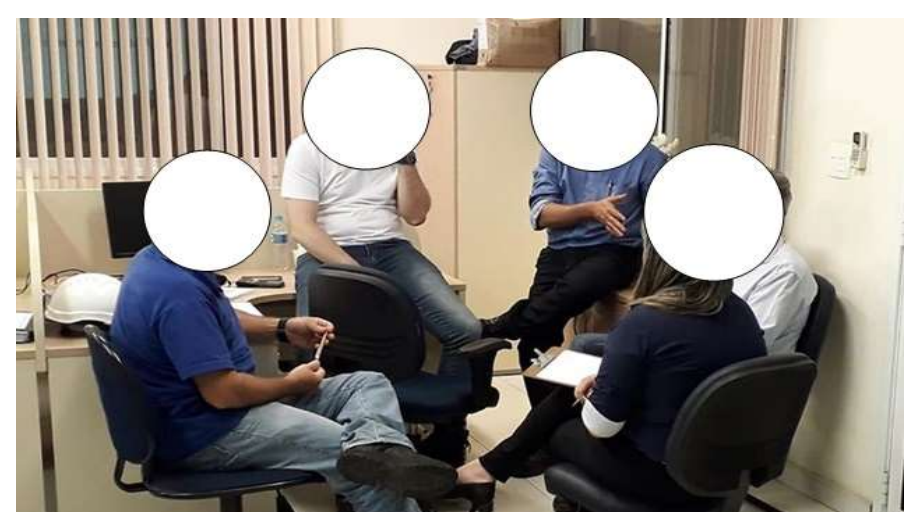

Fonte: Registro fotográfico do autor (2020). 
Figura 5 - Ferramenta "Canvas de Projetos" utilizada durante o workshop.

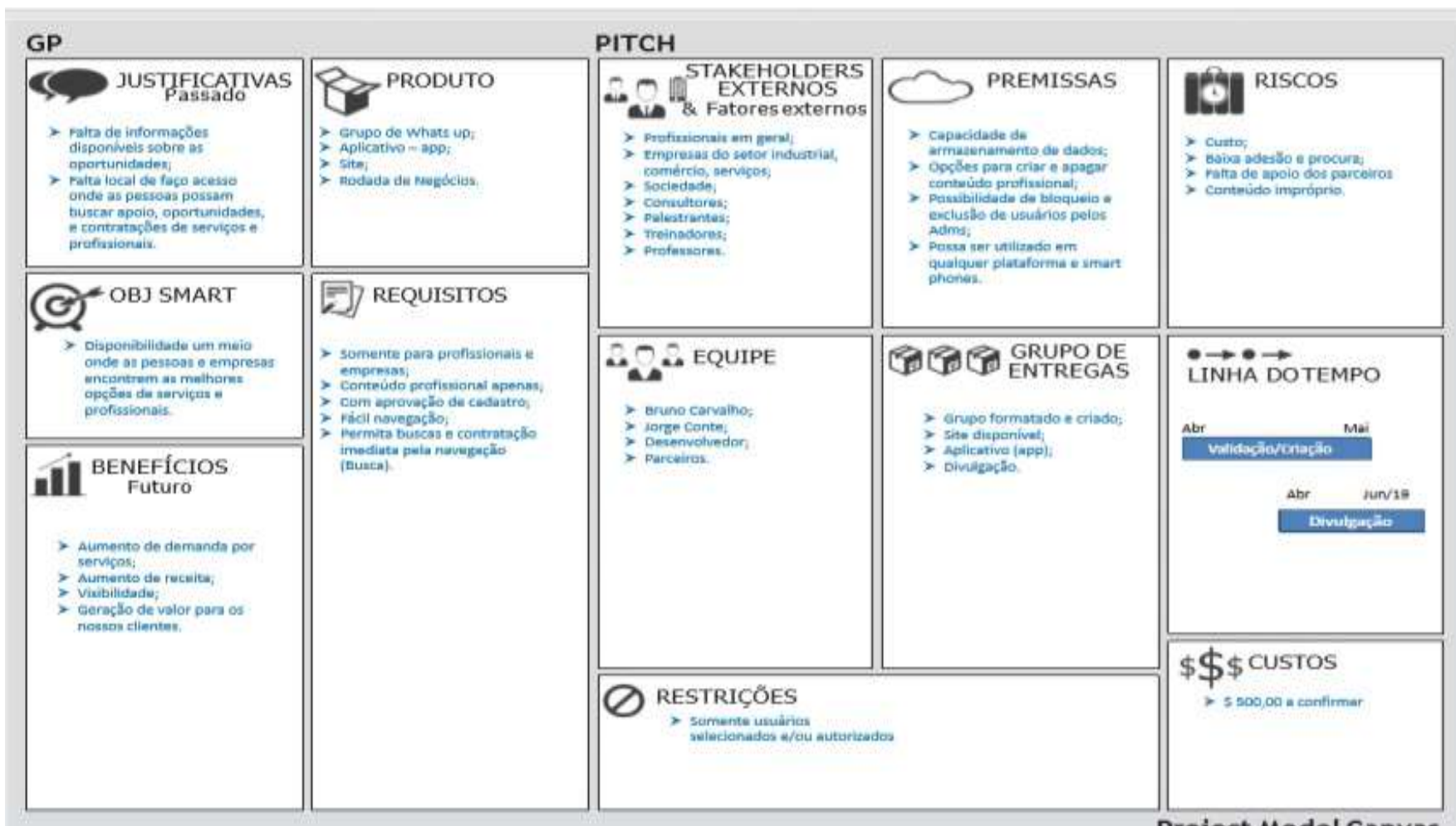

Fonte: Registro fotográfico do autor (2020).

Figura 6 - Momento de brainstorming (tempestade de ideias).

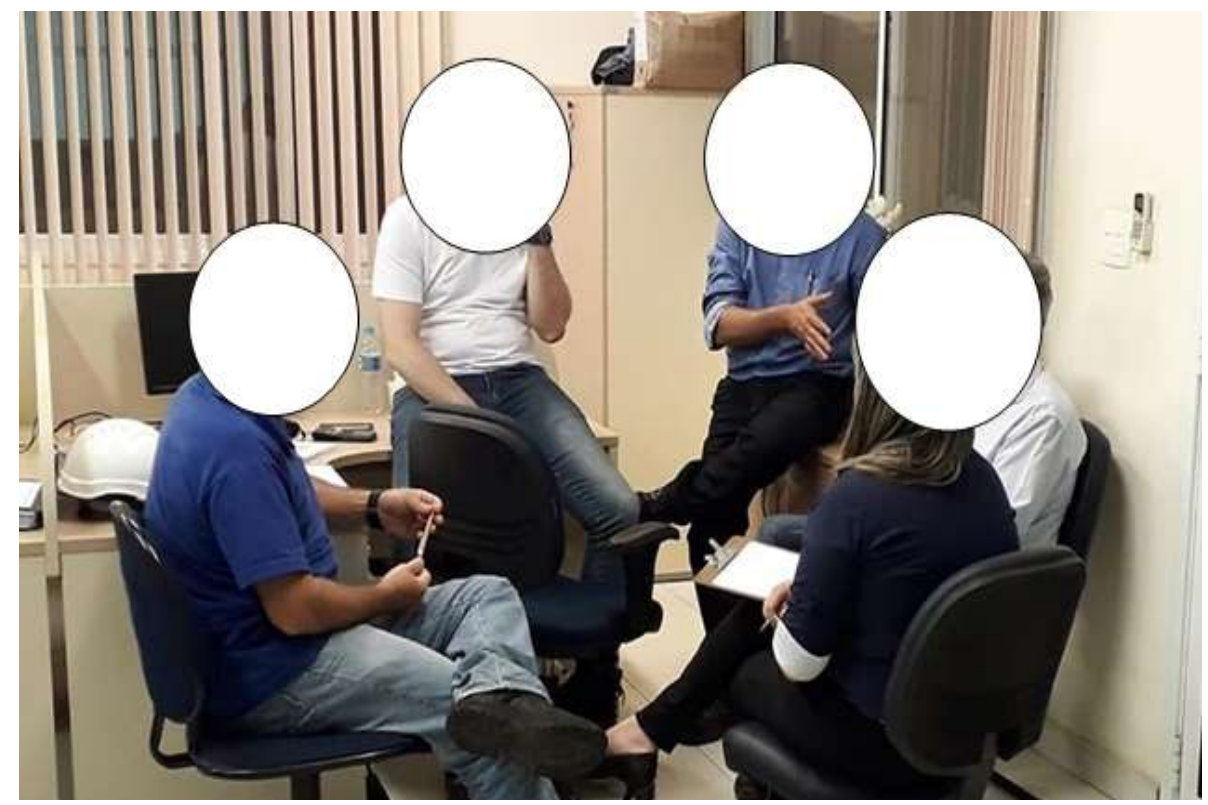

Fonte: Registro fotográfico do autor (2020). 
Figura 7 - Momento da prototipação.

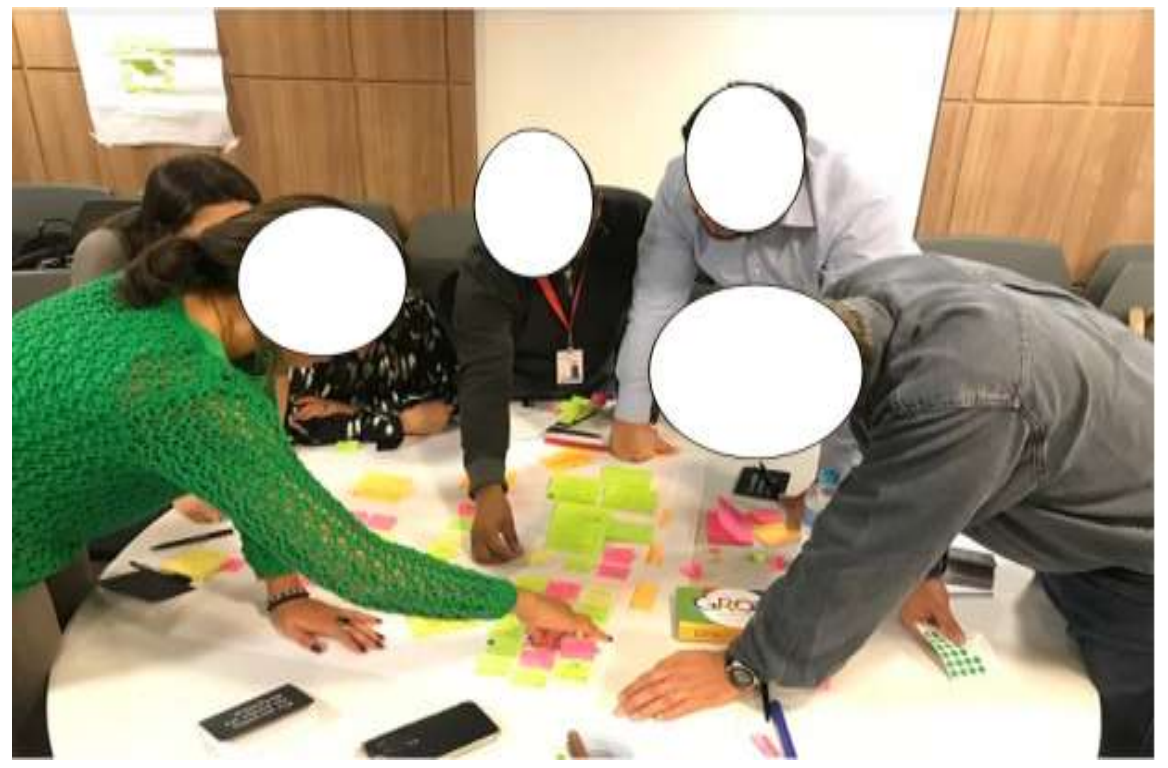

Fonte: Registro fotográfico do autor (2020).

\section{Resultados e Discussão}

Os resultados obtidos estão baseados na tabulação das respostas relatadas nos questionários aplicados, pré e pós workshop.

\subsection{Questionário Pré-Workshop}

O questionário pré-workshop teve como objetivo levantar as percepções e conhecimento dos participantes sobre o tema Design Thinking, se as pessoas que trabalham com projetos têm vivenciado alguns dos seus valores principais, quais resultados são alcançados e também identificar em qual proporção o departamento de gestão de projetos, ou os setores que usam dessa metodologia de gestão tem participado e contribuído com os objetivos estratégicos de suas respectivas empresas.

Esse instrumento de pesquisa foi aplicado logo no início da atividade e sem que nenhum conteúdo ou conceito fosse apresentado, trouxe os seguintes resultados: A primeira questão foi aplicada nas reuniões estratégicas, e nela buscou-se entender se esses departamentos participam de discussões onde as decisões estratégicas são tomadas (Gráfico 1).

Gráfico 1 - Pergunta $N^{\circ}$ 1: Em minha organização, o Departamento ou Setor que utiliza Gestão de Projetos participa frequentemente de reuniões que envolvem decisões estratégicas da empresa.

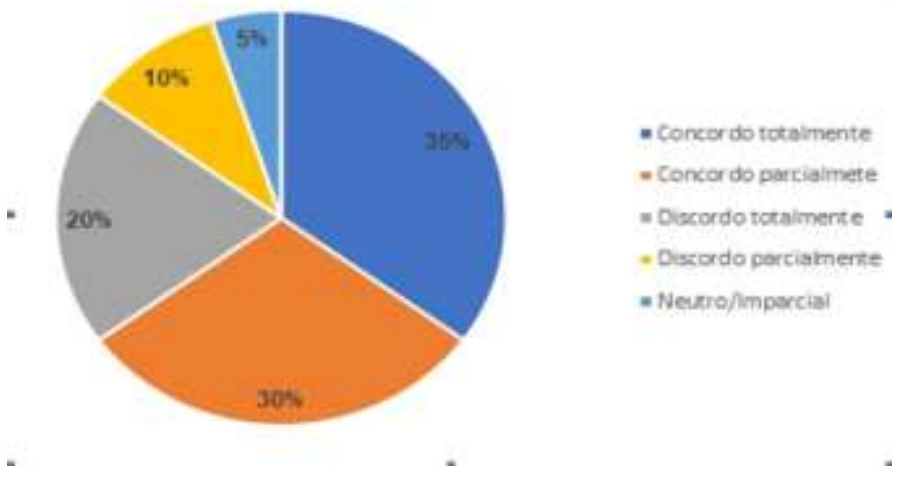

Fonte: Dados da Pesquisa, autores (2020). 
A segunda questão foi sobre gestão de projetos como área estratégica, com o intuito de observar se, na visão desses profissionais, a empresa compreende que a Gestão de Projetos tem um papel estratégico (Gráfico 2).

Gráfico 2 - Pergunta $\mathrm{N}^{\circ}$ 2: A minha organização compreende plenamente o Departamento de Gestão de Projetos como sendo uma área estratégica para o resultado da empresa de modo a agregar valor ao negócio.

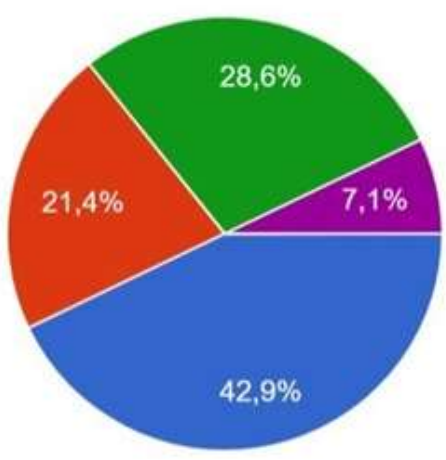

Concordo totalmente

Concordo parcialmente

Não concordo, nem discordo

Discordo parcialmente

Discordo totalmente

Fonte: Dados da Pesquisa, autores (2020).

A terceira questão visa avaliar o grau de conhecimento da equipe que atua em gestão de projetos sobre o Design Thinking (Gráfico 3).

Gráfico 3 - Pergunta $\mathrm{N}^{\circ}$ 3: Considerando sua equipe e a estrutura da sua organização e a forma como atuam em gestão de projetos, como você avalia o nível de conhecimento desta equipe sobre Design Thinking?

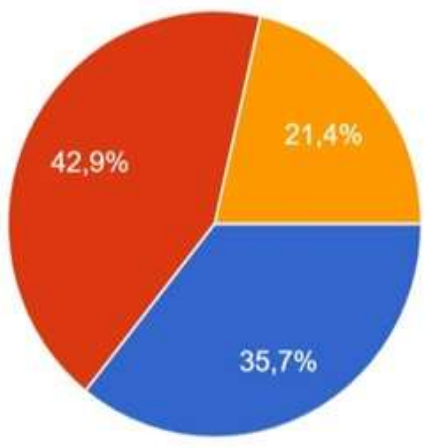

Nenhum conhecimento

Já ouviu falar mas não sabe bem o que é

Conhece parcialmente o Design Thinking e tem uma pequena noção para que ele serve

Tem bom conhecimento sobre Design Thinking

Conhece amplamente e sabe usar na prática.

Fonte: Dados da Pesquisa, autores (2020)

A questão número quatro "Quais são os principais temas/assuntos que demandam na empresa a elaboração de projetos?" tem o objetivo de descobrir, entre alguns temas comuns, quais deles demandariam a elaboração de projetos (Gráfico 4). 
Gráfico 4 - Pergunta Nº : Quais são os principais temas/assuntos que demandam na empresa a elaboração de projetos?

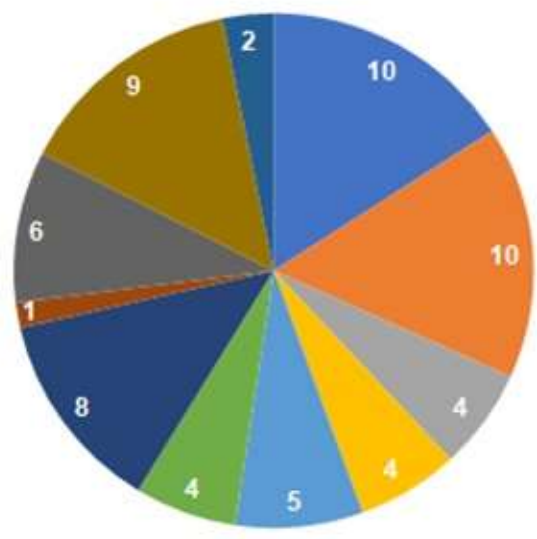

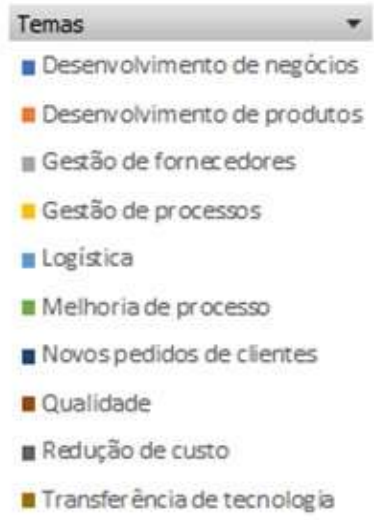

Fonte: Dados da Pesquisa, autores (2020).

A questão número cinco pergunta se a empresa tem utilizado o Design Thinking em projetos (Gráfico 5). A questão número seis é "Caso sua empresa use o Design Thinking em projetos, como você avalia os resultados em comparação as empresas que não se usa o Design Thinking?" (Gráfico 6).

Gráfico 5 - Pergunta $\mathrm{N}^{\circ}$ 5: A empresa tem utilizado o Design Thinking em projetos?

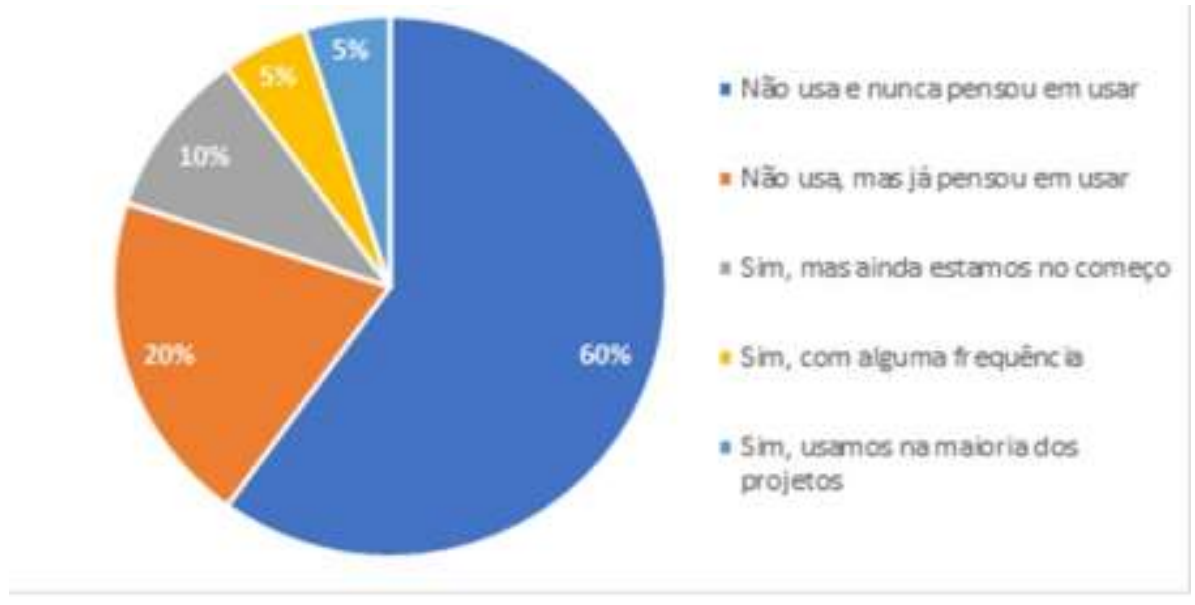

Fonte: Dados da Pesquisa, autores (2020).

A questão número seis trata da comparação das empresas que usam Design Thinking das que não usam (Gráfico 6). 
Gráfico 6 - Pergunta $N^{\circ}$ 6: Caso sua empresa use o Design Thinking em projetos, como você avalia os resultados em comparação as empresas que não se usa o Design Thinking?

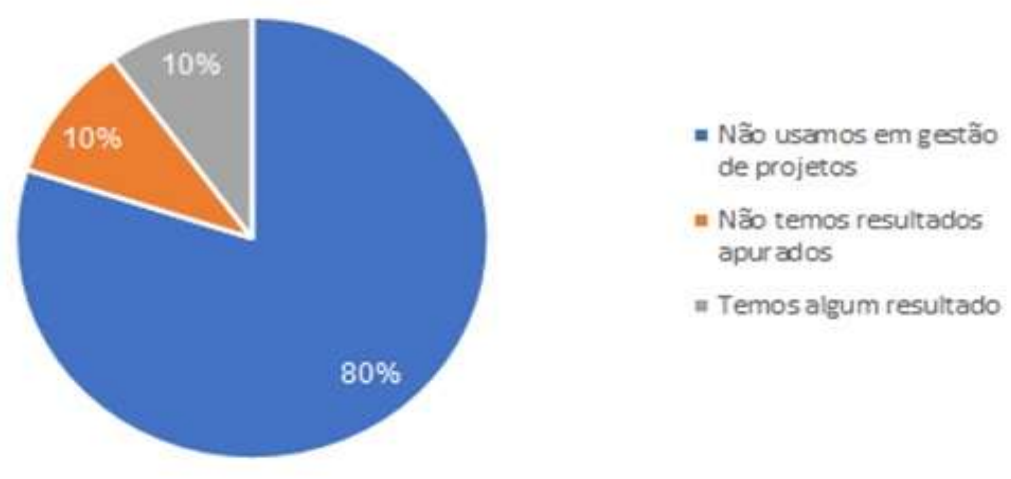

Fonte: Dados da Pesquisa, autores (2020).

A questão número sete objetivou entender qual seria a principal razão ou fator motivador para a utilização dessa abordagem (Gráfico 7).

Gráfico 7 - Pergunta $N^{\circ}$ 7: Se sua empresa não usa o Design Thinking em projetos, você acredita que a motivação para utilizar seria qual? Ou, se já utiliza, qual é a motivação atual?
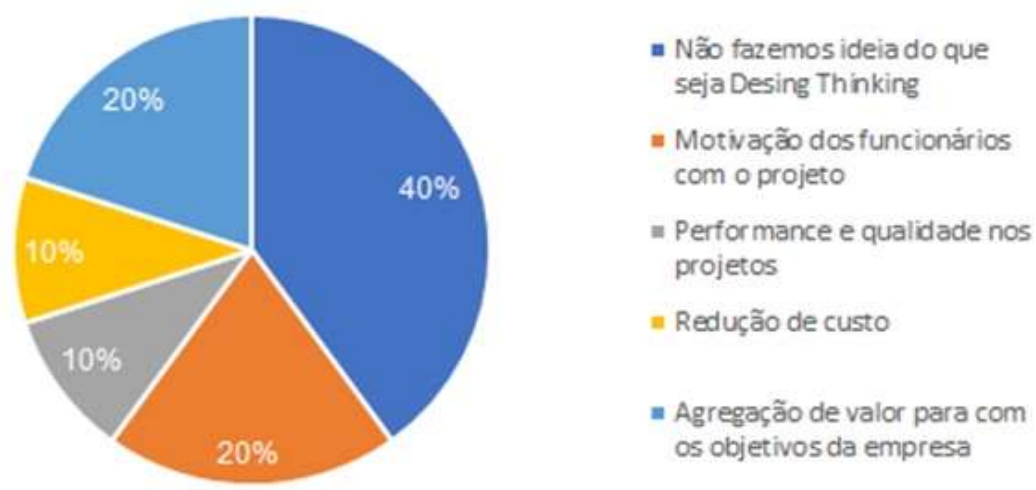

Fonte: Dados da Pesquisa, autores (2020).

Na questão número oito, "A equipe de projetos atua totalmente focada e inspirada na identificação das necessidades das partes interessadas para as quais está desenvolvendo projetos". Observou-se o quanto estão vivenciando um valor importante para o pensamento de Design, que é a identificação de necessidades das pessoas (empatia) envolvidas nos projetos (Gráfico 8). 
Gráfico 8 - Equipe de projetos e a identificação de necessidades.

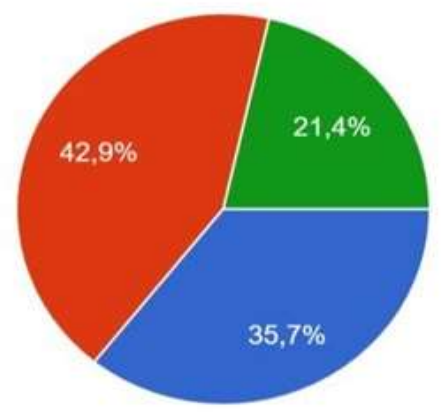

Concordo totalmente

Concordo parcialmente

Não concordo, nem discordo

Discordo parcialmente

Discordo totalmente

Fonte: Dados da Pesquisa, autores (2020).

Na questão número nove, buscou-se entender se a equipe de projetos considera a empatia, e algumas das possíveis metodologias de imersão, bem como a colaboração como algo que vem sendo aplicado (Gráfico 9).

Gráfico 9 - A equipe busca constantemente a seleção de ideias centradas na resolução de problemas ou necessidades, interagindo e engajando as pessoas de maneira colaborativa por meio de diferentes técnicas como: entrevistas, observações, imersão e uma boa gestão de comunicação.

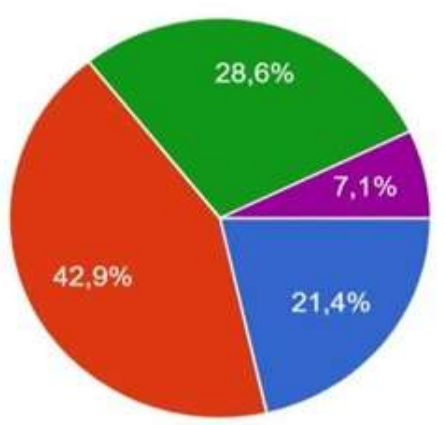

Concordo totalmente

Concordo parcialmente

Nāo concordo, nem discordo

Discordo parcialmente

Discordo totalmente

Fonte: Dados da Pesquisa, autores (2020).

A prática da prototipação aparece na décima questão (Gráfico 10), e os resultados dos projetos são pesquisados na questão número onze (Gráfico 11). 
Gráfico 10 - Pergunta $\mathrm{N}^{\circ} 10$ : Os novos projetos ou programas desenvolvidos e executados pela equipe de gestão de projetos que visam solucionar um problema ou atender a uma necessidade da empresa são constantemente testados e obtidos feedback dos usuários.

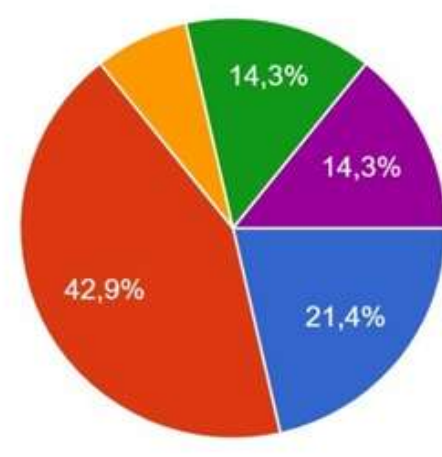

Concordo totalmente

Concordo parcialmente

Não concordo, nem discordo

Discordo parcialmente

Discordo totalmente

Fonte: Dados da Pesquisa, autores (2020).

Gráfico 11 - Pergunta $N^{\circ}$ 11: resultados dos projetos são pesquisados na questão número onze: "Como você avalia, atualmente, os resultados dos projetos de gestão em sua organização?” (Gráfico 11).

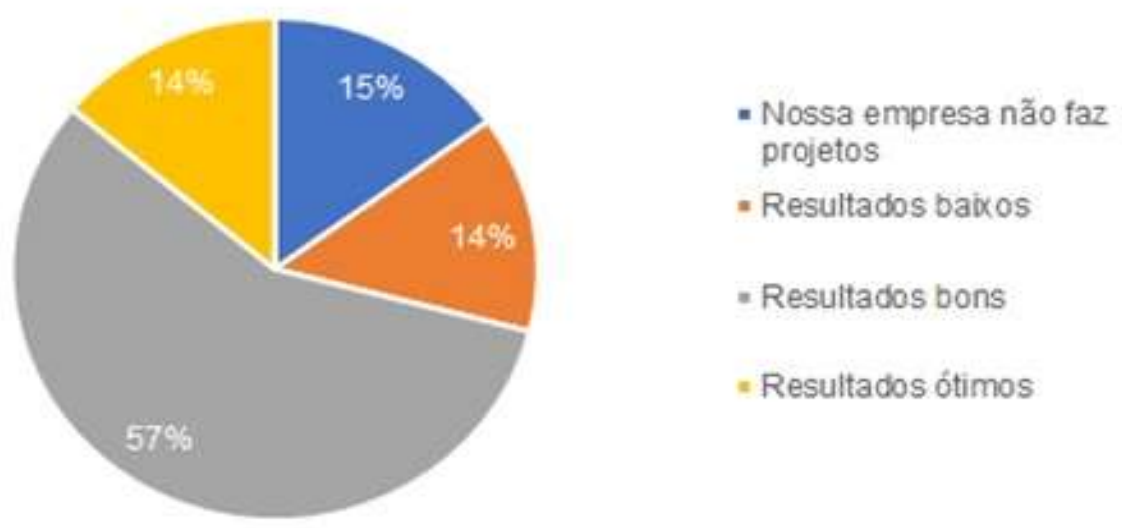

Fonte: Dados da Pesquisa, autores (2020).

\subsection{Questionário Pós-Workshop}

O questionário pós-workshop/treinamento foi aplicado após o término da apresentação dos conteúdos e das práticas aplicadas no workshop.

O objetivo foi observar o quanto o Design Thinking pode contribuir para os projetos e resultados esperados pela empresa, bem como se ele auxilia na vivência de algumas práticas importantes na elaboração de projetos, práticas essas que chamamos de melhores práticas do gerenciamento de projetos. Também considerou-se alguns possíveis fatores que podem dificultar a sua utilização. Por fim, o questionário também avaliou a satisfação dos participantes com o workshop/treinamento.

A primeira questão desse questionário foi quanto aos ganhos com o us do Design Thinking (Gráfico 12). 
Gráfico 12 - Pergunta $N^{\circ} 1$ : Você acredita que a empresa poderá ter ganhos ao utilizar o Design Thinking em gestão de projetos de Ganhos com o uso do Design Thinking?

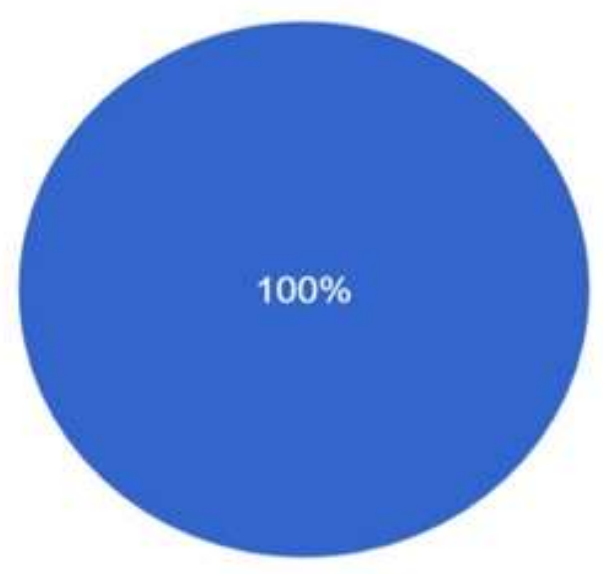

Sim

Fonte: Dados da Pesquisa, autores (2020)

A segunda questão é sobre a possibilidade de resultado com o Design Thinking (Gráfico 13).

Gráfico 13 - Pergunta №2: Como você avalia a possibilidade de resultados na sua empresa, comparando os projetos usando o Design Thinking com os projetos em que não se usa o Design Thinking?

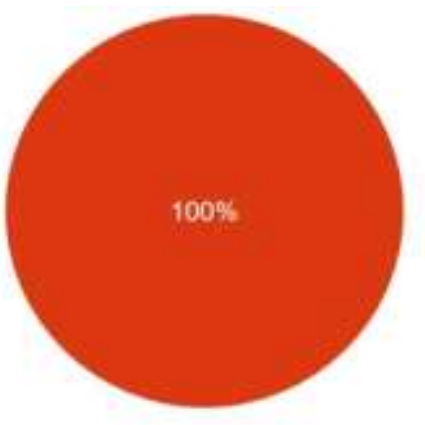

Năo acredito que existirăo resultados relevantes que sejam diferentes dos projetos sem o uso do Design Thinking

Acredito que teremos resultados melhores com o uso do Design Thinking

Fonte: Dados da Pesquisa, autores (2020).

A terceira questão compara os resultados dos projetos com e sem a utilização do pensamento do Design e estipula uma proporção de ganhos nos resultados esperados (Gráfico 14). 
Gráfico 14 - Pergunta No 3: Melhoria de resultados com o Design Thinking.

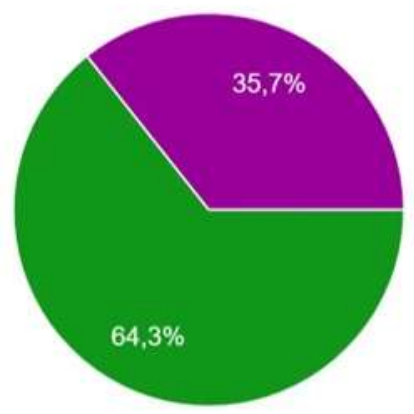

Os projetos com uso de Design Thinking não apresentariam resulta...

Os projetos com uso de Design Thinking apresentariam raríssimos $\mathrm{r}$..

Os projetos com uso de Design Thinking apresentariam alguns pou...

Os projetos com uso de Design

Thinking apresentariam muitos resu...

Os projetos com uso de Design

Thinking apresentariam resultados...

Fonte: Dados da Pesquisa, autores (2020).

A pergunta número quatro permitiu que os respondentes marcassem mais de um item de resposta se assim desejassem, e identifica quais os resultados esperados da utilização do Design Thinking (Gráfico 15).

Gráfico 15 - Pergunta $\mathrm{N}^{\circ}$ 4: Com a utilização do Design Thinking em projetos, quais dos resultados abaixo devem acontecer? (Marcar quantas alternativas forem necessárias).

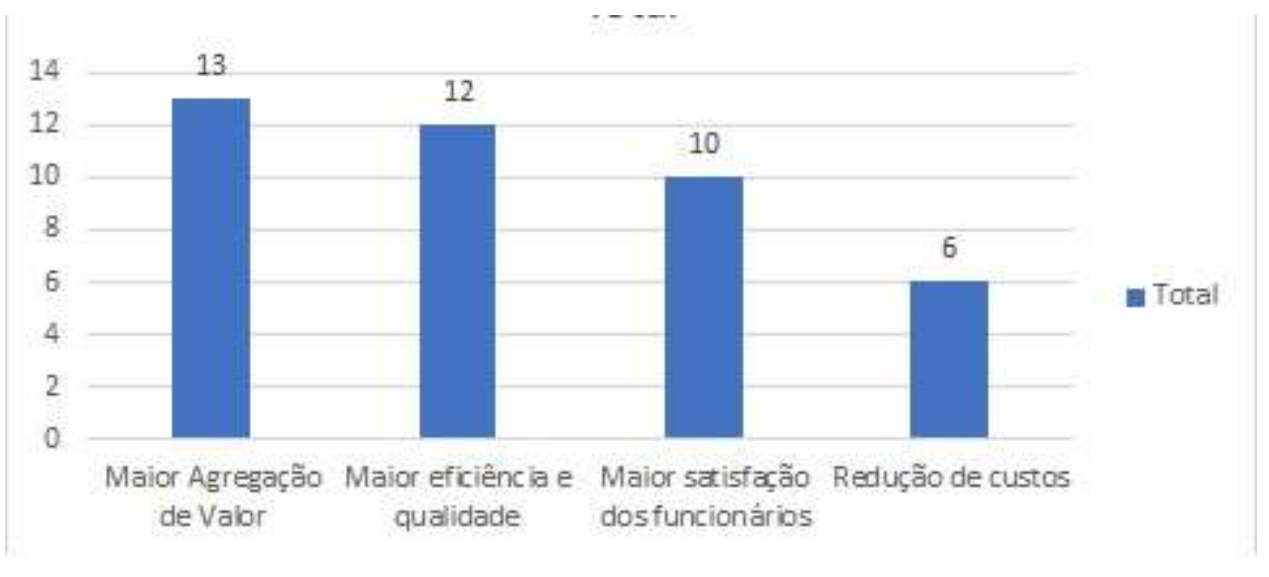

Fonte: Dados da Pesquisa, autores (2020)

A quinta questão objetivou identificar quais temas, dentre aqueles que foram sugeridos idênticos aos do primeiro questionário, o Design Thinking poderiam ser utilizados, classificados em uma escala de importância (Gráfico 16).

Os temas tratados foram:

$>$ Desenvolvimento de novos negócios

$>$ Melhoria de processo

$>$ Redução de custo

$>$ Gestão de processos

$>$ Novos pedidos de clientes

$>$ Gestão de fornecedores

$>$ Treinamentos gerais e/ou em gestão de projetos

$>$ Logística

$>$ Treinamentos comportamentais

$>$ Transferência de tecnologia 
Desenvolvimento de novos produtos e serviços

Gráfico 16 - Pergunta $\mathrm{N}^{\circ}$ 5: Quais são os principais temas/assuntos que demandam a elaboração de projetos e que você avalia que seriam importantes para utilizar o Design Thinking?

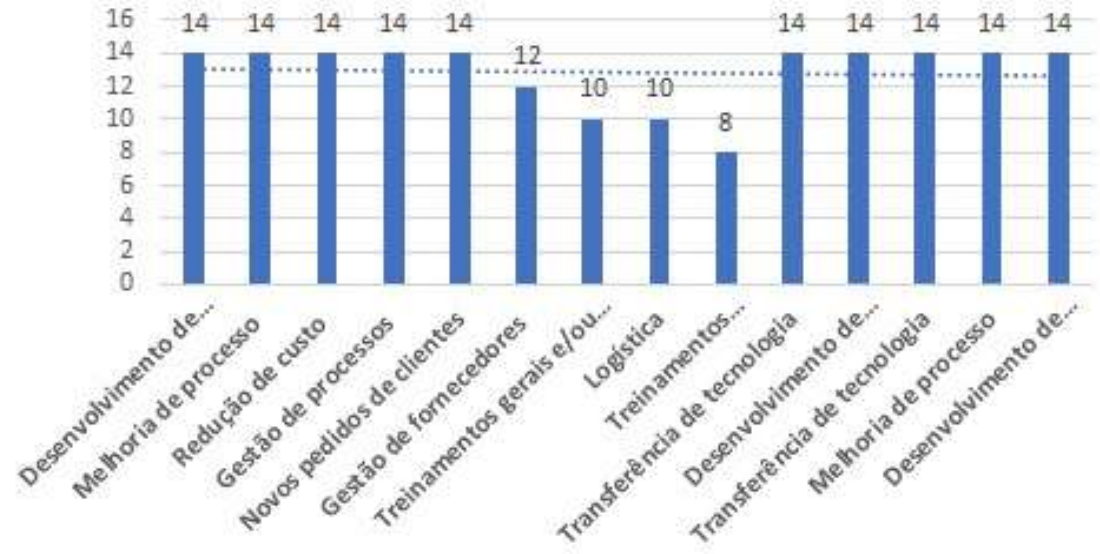

Fonte: Dados da Pesquisa, autores (2020).

A sexta questão foi direcionada no Design Thinking e as necessidades das partes interessadas (Gráfico 17).

Gráfico 17 - Pergunta N$^{\circ}$ 6: Eu acredito que com o Design Thinking a equipe atuará mais focada e inspirada na identificação das necessidades das pessoas, clientes e sociedade (partes interessadas) para as quais está desenvolvendo projetos.

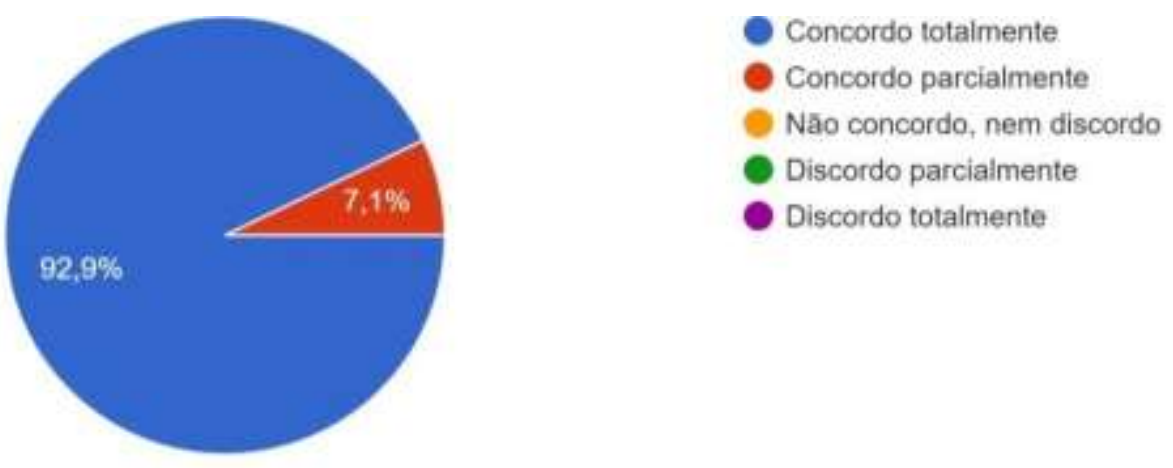

Fonte: Dados da Pesquisa, autores (2020)

A sétima questão apresenta os valores de imersão, empatia e colaboração (Gráfico 18), e aoitava questão trata sobre a prototipação (Gráfico 19). 
Gráfico 18 - Pergunta $\mathrm{N}^{\circ}$ 7: Eu acredito que, com o Design Thinking, a equipe buscará com maior frequência a coleta e seleção de ideias centradas na resolução de problemas ou necessidades (das partes interessadas), interagindo e engajando as pessoas de maneira colaborativa por meio de diferentes técnicas como, entrevistas, observações, imersão, etc.

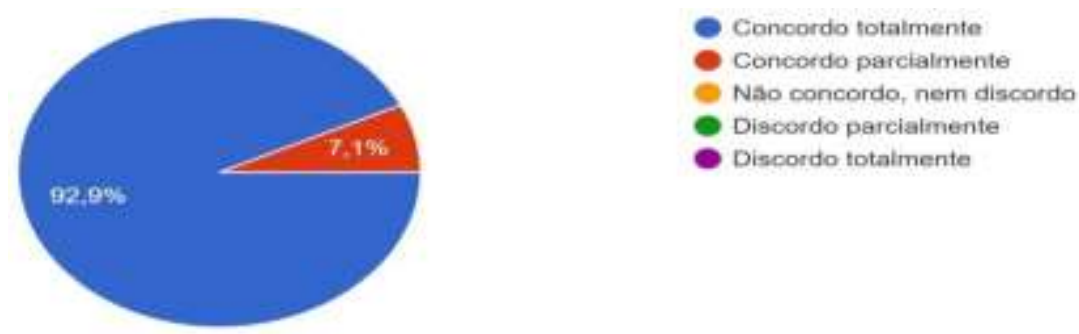

Fonte: Dados da Pesquisa, autores (2020).

Gráfico 19 - Pergunta $\mathrm{N}^{\circ}$ 8: Eu acredito que com o Design Thinking na gestão de projetos ou programas que visam solucionar um problema ou atender a uma necessidade (partes interessadas) serão frequentemente testados e obtidos feedback dos usuários

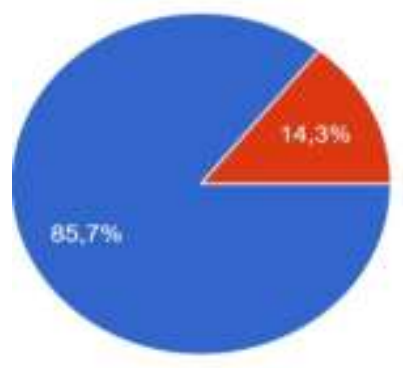

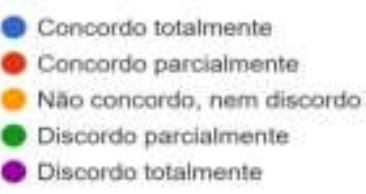

Discordo totalmente

Fonte: Dados da Pesquisa, autores (2020).

A nona questão trata da disposição para utilização do Design Thinking. (Gráfico 20). A questão número dez teve a resposta aberta e livre, e do total de 10 respondentes, 7 apresentaram motivos diversos para a pergunta sobre fatores de dificuldade da utilização do Design Thinking (Gráfico 21).

Gráfico 20 - Pergunta No 9: Qual é o grau de disposição e interesse da equipe em utilizar o Design Thinking como metodologia para os projetos da empresa?

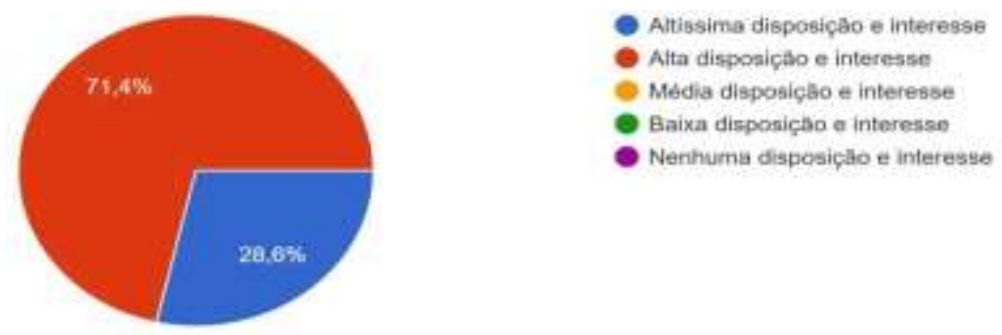

Fonte: Dados da Pesquisa, autores (2020). 
Gráfico 21 - Pergunta No 10: Quais seriam possíveis motivos que dificultariam a utilização do Design Thinking na gestão de projetos? (resposta livre)

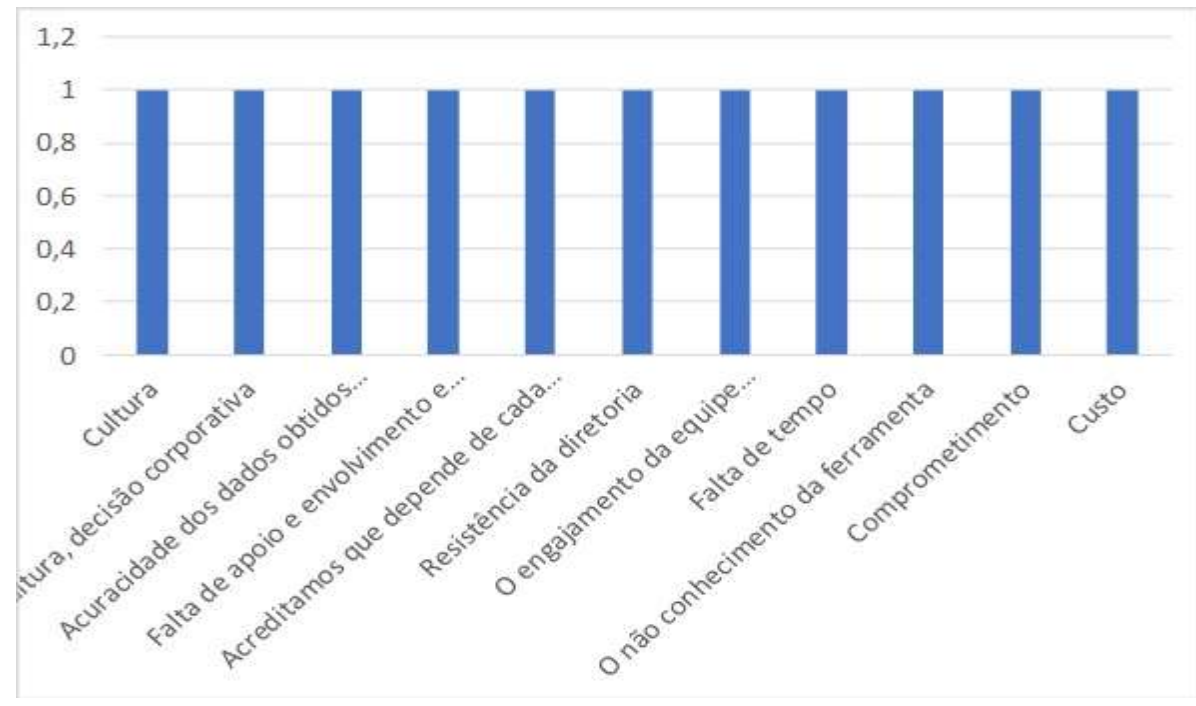

Fonte: Dados da Pesquisa.

A décima primeira questão avalia a satisfação com o workshop/Treinamento pelo grau de aprendizado. A insatisfação com o treinamento proporcionado pelo workshop poderia impactar na percepção em relação à eficácia do Design Thinking e sua aplicação, e coletar esse feedback é muito útil para a melhoria do processo (Gráfico 22).

Gráfico 22 - Pergunta $\mathrm{N}^{\circ}$ 11: Como você avalia o grau de aprendizado de seu grupo ou para você?

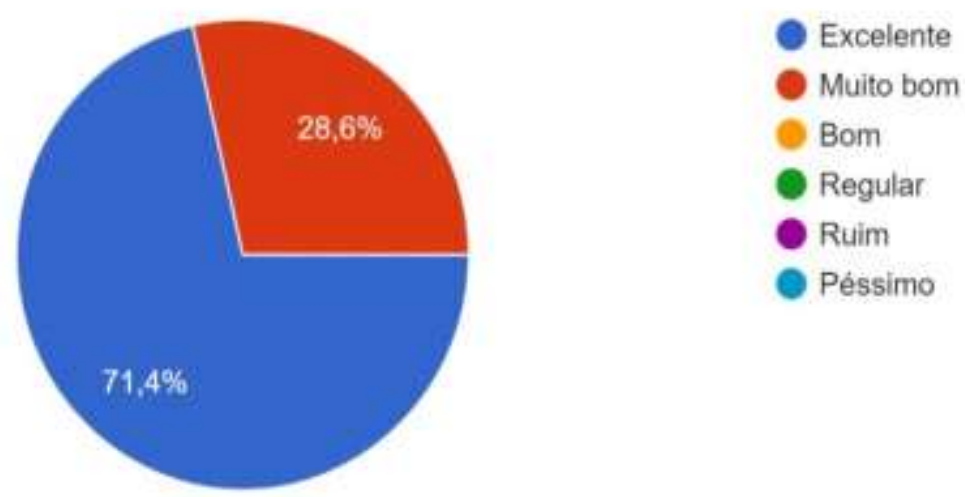

Fonte: Dados da Pesquisa, autores (2020).

Com a aplicação do segundo questionário ao término dos dois workshops, constatou-se que a ampla maioria dos profissionais compreenderam a metodologia do Design Thinking e que sua aplicação na gestão de projetos trará ganhos para as empresas. Ainda que tenham apontado elevado interesse e disposição de utilização do Design Thinking, verificou-se possíveis entraves organizacionais para sua implementação como, a cultura organizacional, a falta de apoio, resistências internas e desconhecimento, bem como de novos investimentos em capacitação. 


\section{Considerações Finais}

O workshop de Design Thinking, como base projetual para a gestão de projetos, demonstrou-se como uma ação estratégica eficaz e com grande potencial de gerar ótimos resultados.

As percepções, considerações e conclusões, após a tabulação dos dados, revelam que:

Todos os participantes afirmaram que o Design Thinking tem condições de gerar resultados muito superiores, inclusive se comparados com os resultados alcançados pelos atuais projetos sem a utilização dele. Isso pode ser muito relevante, pois as próprias pessoas disseram que os resultados atuais são predominantemente razoáveis. Isso confirma as hipóteses de que é possível a utilização do Design Thinking na gestão de projetos e que essa abordagem é capaz de gerar melhores resultados do que quando não se usa o Design Thinking.

A liderança das empresas pesquisadas apresenta uma boa participação nos assuntos estratégicos da empresa, porém, segundo os próprios profissionais de gestão de projetos, nem todos enxergam a agregação de valor das suas ações. Sabendo que o Design Thinking utiliza a empatia, a colaboração e a prototipação como valores essenciais, a sua prática nos projetos irá gerar mais alinhamento, participação, visibilidade e resultados esperados e contratados.

A abordagem do Design Thinking ainda é desconhecida da maioria dos profissionais que atuam com gestão de projetos. Considerando que a pesquisa incluiu um workshop sobre o tema, contribuiu-se para que o tema se tornasse mais popular entre esses profissionais. Entretanto, ainda existe uma grande lacuna de desconhecimento que deve ser minimizada com o passar do tempo, considerando que o assunto ainda se encontra em expansão.

Outros pesquisadores poderão dar continuidade à pesquisa, ampliando o escopo para outros tipos de organizações e projetos que não se restrinjam à gestão de projetos, mas que possam buscar incentivos à utilização em outras disciplinas e departamentos.

Como o tema Design Thinking ainda parece ser desconhecido da grande maioria, as universidades e escolas de design têm um papel importante nessa popularização. Um ótimo caminho para isso é realizar, a exemplo do workshop aplicado nessa pesquisa, alguns encontros, palestras e eventos com a comunidade empresarial.

\section{Referências}

Alves, F. (2016). Design de Aprendizagem com Uso de Canvas. DVS Editora.

Bayer, J. et al. (2017) Migrating the Classical Pen-and-Paper Based Conceptual Sketching of Architecture Plans Towards Computer Tools - Prototype Design and Evaluation. In: Lamiroy B., Dueire Lins R. Graphic Recognition. Current Trends and Challenges. GREC 2015. Lecture Notes in Computer Science, vol 9657. Springer, Cham. https://doi.org/10.1007/978-3-319-52159-6_4

Ben Mahmoud-Jouini, S., Midler, C., \& Silberzahn, P. (2016). Contributions of design thinking to project management in an innovation context. Project Management Journal, 47: 144-156.

Bersin, J. (2016). Deloitte Global Human Capital. Deloitte.

Boudreau, J. \& Cascio, W. (2017), "Human capital analytics: why are we not there?", Journal of Organizational Effectiveness: People and Performance, 4(2), 119-126. https://doi.org/10.1108/JOEPP-03-2017-0021

Brown, T. (2010). Design Thinking - Uma Metodologia Poderosa para Decretar o Fim das Velhas ideias. Elsevier.

Brown, T. \& Wyatt, J. (2010). Design Thinking for Social Innovation. Stanford Social Innovation Review.

Calôba, G., \& Klaes, M. (2018). Gerenciamento de Projetos com PDCA - Conceitos e técnicas para planejamento, monitoramento e avaliação do desempenho de projeto e portfólios. Starlin Alta Editora.

Cavalcanti, C. M. C. (2014). Design Thinking como metodologia de pesquisa para concepção de um ambiente virtual de aprendizagem centrado no usuário. Simpósio Internacional de Educação a Distância, Universidade Federal de São Carlos.

Cervo, A. L., Bervian, P. A., \& Da Silva, R. (2007). Metodologia científica. (6a ed.), Pearson Prentice Hall.

Finocchio, J. J. (2013). Project Model Canvas - Gerenciamento de Projetos Sem Burocracia. Alta Books.

Gonsalves, E. P. (2011). Conversas sobre iniciação à pesquisa científica. (5a ed.), Editora Alínea. 
Research, Society and Development, v. 10, n. 8, e43210817532, 2021

(CC BY 4.0) | ISSN 2525-3409 | DOI: http://dx.doi.org/10.33448/rsd-v10i8.17532

Guldmann, E., Bocken, N. M. P., \& Brezet, H. (2019). A Design Thinking Framework for Circular Business Model Innovation: Special Issue: Sustainable Value Creation Through Business Models. 7.

Layton, M. C., Ostermiller, S. J., \& Kynaston D. J. (2020). Agile Project Management for Dummies. John Wiley \& Sons.

Liedtka, J. \& Ogilvie, T. (2016). A Magia do Design Thinking - Um Kit de ferramentas para o crescimento rápido de sua empresa. HSM Editora.

Logan, R. K. (2012). Design Thinking, Strategic Foresight, Business Model Generation and Biology: A Mashup. Conference paper for use in workshops at MaRS and in the Think Tank course at OCAD University. Ontario College of Arts and Design University. Ontário - CN. https://www.researchgate.net/publication/267037971

Lima, F. S., \& Yoshitake, M. (2016). Accounting in the Administration of Enterprises Bacabalenses: A Study on the Decision-Making. Journal of Finance and Accounting. 4(1), 18-24. 10.11648/j.jfa.20160401.13

Lourenço, F., Li, Z., Ren, L. \& Cheng, R. (2021). What Retail Experts Say about Tourism Retail Education? A Case of Macao Using an Integrated BloomKolb Learning Design Canvas, Journal of Quality Assurance in Hospitality \& Tourism, 10.1080/1528008X.2021.1920549

Melo, A. \& Abelheira, R. (2015). Design Thinking \& Thinking Design - Metodologia, ferramentas e reflexões sobre o tema. Novatec.

Novaes, A., Ornellas, M. d., \& Ens, R. T. (2017). Convergências teóricas em representações sociais e seu aporte para o estudo de políticas docentes. Revista Diálogo Educacional, 17(53), 999-1015. 10.7213/1981-416X.17.052.AO14

Osterwalder, A. \& Pigneur, Y. (2011). Business Model Generation: Inovação em Modelo de Negócios. Rio de Janeiro: Alta Books.

Park, M., Yi, M., Flores, R., \& Nguyen, B. (2020). Informal Formative Assessment Conversations in Mathematics: Focusing on Preservice Teachers' Initiation, Response and Follow-up Sequences in the Classroom. Eurasia Journal of Mathematics, Science and Technology Education, 16(10), https://doi.org/10.29333/ejmste/8436

Paschini, S. (2006). Estratégia - Alinhando a Cultura Organizacional e a Estratégia de RH à Estratégia de Negócios. Qualitymark.

Poikela, S. \& Lähteenmäki, M. (2006). Mentoring Tutor's Professional Growth. In Poikela, E.; Nummenmaa, A. R. Understanding Problem-Based Learning.

Raynor, K. E. (2017). Defining the Density Debate: Social Representations of Urban Consolidation in Brisbane, PhD Thesis, Brisbane, Queensland University of Technology, $299 \mathrm{p}$.

Shivers-McNair, A., Phillips, J., Campbell, A., Mai, H. H., Yan, A., Macy, J. F., \& Guan, Y. (2018). User-Centered Design In and Beyond the Classroom: Toward an Accountable Practice. Computers and Composition, 49, 36-47.

Tacconi, L. (2017). Scientific Methodology. Biodiversity and Ecological Economics, Taylor \& Francis Group, 19 P.

Thompson, J. (2007). Is Education 1.0 Ready for Web 2.0 Students? Innovate: Journal of Online Education, 3(4).

Ulrich, D., Brockbank, W., Younger, J., \& Ulrich, M. (2014). Competências Globais de RH Agregando Valor Competitivo de Fora Para Dentro. Bookman. Vergara, S. C. (2014). Projeto e relatórios de pesquisa em administração. (15a ed.), Atlas.

Vianna, M., Vianna, Y., Adler, I. K., Lucena, B. \& Russo, B. (2012). Design Thinking - Inovação em negócios. MJV Press.

Yalgosheva, M. (2020). Web Tool 2 and its benefits - Academic research in educational sciences. 1 (3). 